\title{
INTRAPERITONEAL INSEMINATION IN THE RABBIT
}

\author{
G. E. ADAMS \\ A.R.C. Unit of Reproductive Physiology and Biochemistry, \\ University of Cambridge*
}

(Received 21st August 1968)

\begin{abstract}
Summary. Fifty-four rabbits were inseminated intraperitoneally 3 to $6 \frac{1}{2} \mathrm{hr}$ before the injection of HCG given to induce ovulation. From 0.3 to $1.0 \mathrm{ml}$ of semen or epididymal spermatozoa, containing 10 to $390 \times 10^{6}$ spermatozoa was inseminated. Thirty-nine of the does were autopsied 17 to $44 \mathrm{hr}$ after HCG. The proportion of eggs recovered varied from 28 to $95 \%$ and was generally inversely related to that of eggs fertilized, which varied from 20 to $79 \%$, excluding eighteen does having practically no fertilization. Poor egg recovery and higher fertilization rates tended to be associated with larger numbers of spermatozoa inseminated. In fifteen does examined by laparotomy on Day 10, eight were pregnant with 28 to $36 \%$ of the ovulations represented by implants, $68 \%$ of which survived to term.

In twenty-five does, inseminated with 100 to $386 \times 10^{6}$ epididymal or ejaculated spermatozoa, $0,10,15$ or $20 \mathrm{hr}$ before giving HCG, 50 to $79 \%$ of the eggs were fertilized, except in the $20-\mathrm{hr}$ group where fertilization failed. Egg recovery improved, from $22 \%$ to a maximum of $91 \%$, as the interval between insemination and ovulation was extended.
\end{abstract}

\section{INTRODUCTION}

In the rabbit, the first attempts to achieve fertilization by intraperitoneal insemination met with very limited success (Hadek, 1958; Rowlands, 1958). At that time it was not known that the capacitation process took considerably longer in the Fallopian tubes than in the uterus (Adams \& Chang, 1962). In accord with this fact, Mroueh \& Mastroianni (1966) have recently found that conception occurred only when the insemination took place simultaneously with or preceding-by up to $4 \mathrm{hr}$ - the ovulating injection. Within these time limits, the proportion of does becoming pregnant (eight out of twelve) was quite satisfactory, but the implantation rate was low in comparison with controls, due, it was suggested, to increased early embryonic mortality. However, the fertilization rate was not examined. Moreover, since the does were killed 8 to 12 days after insemination, the competence of the remaining viable embryos to survive to full term was not established. The present study is concerned with these aspects as well as the investigation of the effect of extending the interval between insemination and ovulation on fertilization. This latter aspect has been

* Postal address: 307 Huntingdon Road, Cambridge. 
referred to briefly elsewhere (Adams, 1968) in comparison with tubal and vaginal insemination.

\section{MATERIALS AND METHODS}

Semen was collected with an artificial vagina from four or more fertile males, depending upon the volume required, and pooled after removal of gel. In the first experiments the semen was concentrated by centrifugation at $1000 \mathrm{rev} / \mathrm{min}$ for $10 \mathrm{~min}$ and removal of some of the seminal plasma. One lot of semen was twice washed with sodium citrate buffer, as described by Hadek (1958). Samples of epididymal spermatozoa were obtained by flushing 1 to $2 \mathrm{ml}$ of $0.9 \%$ saline through the excised cauda epididymidis via the vas deferens. Sperm density was estimated with a Fuchs-Rosenthal haemocytometer. With a few exceptions, penicillin (1000 units $/ \mathrm{ml}$ ) was added to the semen.

A total of eighty-nine does from the Unit's colony was used, usually in batches of three or four. For insemination they were either held in a supine position or suspended by the hind legs, as described by Mroueh \& Mastroianni (1966), after it was found that this position was more convenient. Latterly, does were fasted for $12 \mathrm{hr}$ before insemination. Insemination was done by injection using a Luer-Lock syringe fitted with a No. 15 needle which was introduced into the body cavity through the linea alba mid-way between the ovaries.

In the first series of experiments, fifty-four does received 10 to $390 \times 10^{6}$ spermatozoa in a volume of 0.3 to $1.0 \mathrm{ml}$. Subsequently, at fixed intervals after insemination, ranging from 3 to $6 \frac{1}{2} \mathrm{hr}, 25$ i.u. human chorionic gonadotrophin (Lutormone, Burroughs Wellcome) was given intravenously to induce ovulation which follows about 10 to $12 \mathrm{hr}$ later.

To obtain information on fertilization thirty-nine of the does were killed at $17 \mathrm{hr}$ (two), 25 to $28 \mathrm{hr}$ (twenty-two) or 38 to $44 \mathrm{hr}$ (fifteen) after the ovulating injection. Egg recovery was performed as described by Adams (1956). Whenever the yield of tubal eggs was lower than expected, the uterine horns were also flushed but no eggs were recovered from this source. The remaining fifteen does, plus ten others which had received either epididymal spermatozoa or 'citrated' semen, were palpated 10 days after the HCG injection; any that were diagnosed pregnant were examined by laparotomy to establish the number of corpora lutea and implantations. Subsequently, the does were observed for the outcome of pregnancy.

In a second series containing twenty-five does, insemination was performed at $0,10,15$ or $20 \mathrm{hr}$ before giving the ovulating injection. Generally, half of each group of does received whole semen, the other half epididymal spermatozoa and usually 250 to $350 \times 10^{6}$ spermatozoa were inseminated in $1 \mathrm{ml}$. Egg recovery was performed at 25 to $30 \mathrm{hr}$ (fourteen), $30 \cdot 1$ to $35 \mathrm{hr}$ (three), $35 \cdot 1$ to $40 \mathrm{hr}$ (six) and $40 \cdot 1$ to $43 \mathrm{hr}$ (two) after the HCG injection.

\section{RESULTS}

Series 1. Egg recovery and fertilization

The numbers of ovulations, eggs recovered and fertilized, together with details of the interval between insemination and HCG injection and number of 


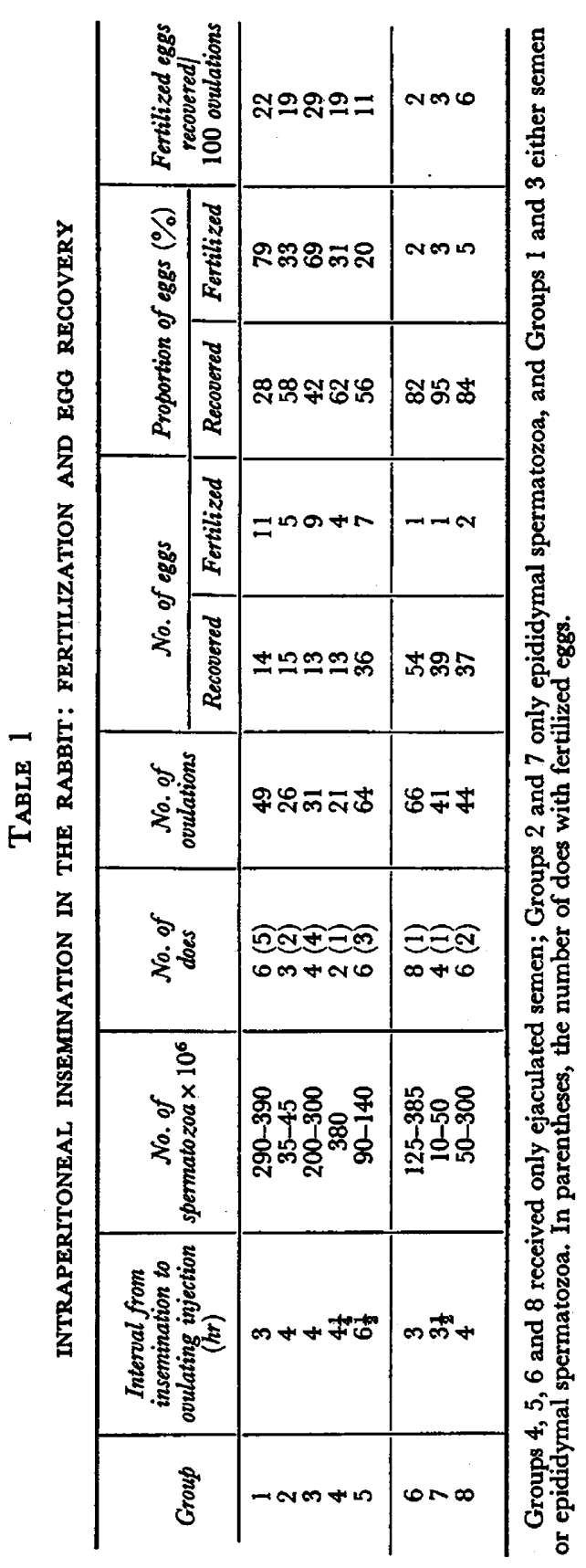


spermatozoa inseminated are given in Table 1. Groups of does in which very few eggs were fertilized are treated separately (Groups 6 to 8 ).

In Groups 1 to 5 the proportion of eggs recovered from the tubes was considerably lower than expected, varying from 28 to $62 \%$, and, with the exception of Group 4, was inversely related to the number of spermatozoa inseminated. In Groups 6 to 8, where fertilization was minimal, the proportion of eggs recovered, 82 to $95 \%$, approached the normal range.

The proportion of eggs fertilized varied from 20 to $79 \%$ (Groups 1 to 5), and the stage of development of the fertilized eggs was equal to that of a normal series, indicating that fertilization was not delayed. Groups 1 to 3 showed an inverse relationship between the level of fertilization and egg recovery, which in turn was related to the number of spermatozoa inseminated. To evaluate the effect of this interaction 'the number of fertilized eggs recovered per 100 eggs ovulated' was calculated (see final column of Table 1). On this basis the variation between Groups 1 to 5 is seen to be quite small.

TABLE 2

INTRAPERITONEAL INSEMINATION IN THE RABBIT: IMPLANTATION AND MAINTENANCE OF PREGNANGY

\begin{tabular}{c|c|c|c|c|c|c|c|c|}
\hline Group & $\begin{array}{c}\text { Interval from } \\
\text { insemination to } \\
\text { ovulating injection } \\
\text { (hr) }\end{array}$ & $\begin{array}{c}\text { No. } \\
\text { spermatozoa } \\
\text { injected } \\
\times 10^{6}\end{array}$ & \multicolumn{3}{|c|}{ No. of does } & \multicolumn{3}{|c|}{ In does pregnant on Day 10} \\
\hline 1 & 4 & Inseminated & $\begin{array}{c}\text { Pregnant } \\
\text { Day 10 }\end{array}$ & Littered & $\begin{array}{c}\text { Corpora } \\
\text { lutea }\end{array}$ & Implants & $\begin{array}{c}\text { Young } \\
\text { born }\end{array}$ \\
\hline 2 & 5 & 200 & 5 & 5 & 4 & 50 & 18 & 10 \\
3 & 4 & $365-450$ & 10 & 3 & 2 & 35 & 10 & 9 \\
4 & 4 & $185 *$ & 5 & 2 & 2 & 23 & 4 & 3 \\
\hline
\end{tabular}

* Epididymal spermatozoa. † Ejaculated, citrated semen.

Implantation and maintenance of pregnancy. Details of the twenty-five does that were examined on the 10th day of pregnancy are given in Table 2. In the first two groups, which received whole semen, eight out of fifteen became pregnant. In these, the number of implantations was quite low (28 to $36 \%$ ) but in keeping with the observations on fertilization. All except one of the twenty-eight conceptuses were normal in size (Adams, 1960). Six of the eight does maintained the pregnancy to term and nineteen healthy young were born.

The insemination of semen twice washed with sodium citrate buffer (Group 4) gave very similar results to those obtained with epididymal spermatozoa (Group 3); in both cases two out of five does became pregnant, and the implantation rates were 15 and $17 \%$.

Series 2. Effect of extending the interval between insemination and ovulation on fertilization and egg recovery

When insemination was carried out at $0,10,15$ or $20 \mathrm{hr}$ before giving the ovulating injection, the proportion of eggs fertilized remained quite high up to $15 \mathrm{hr}$, when it was $59 \%$; however, at $20 \mathrm{hr}$ it was zero (Table 3 ). As in the previous series, egg recovery was affected, being extremely low, $22 \%$, at $0 \mathrm{hr}$. 


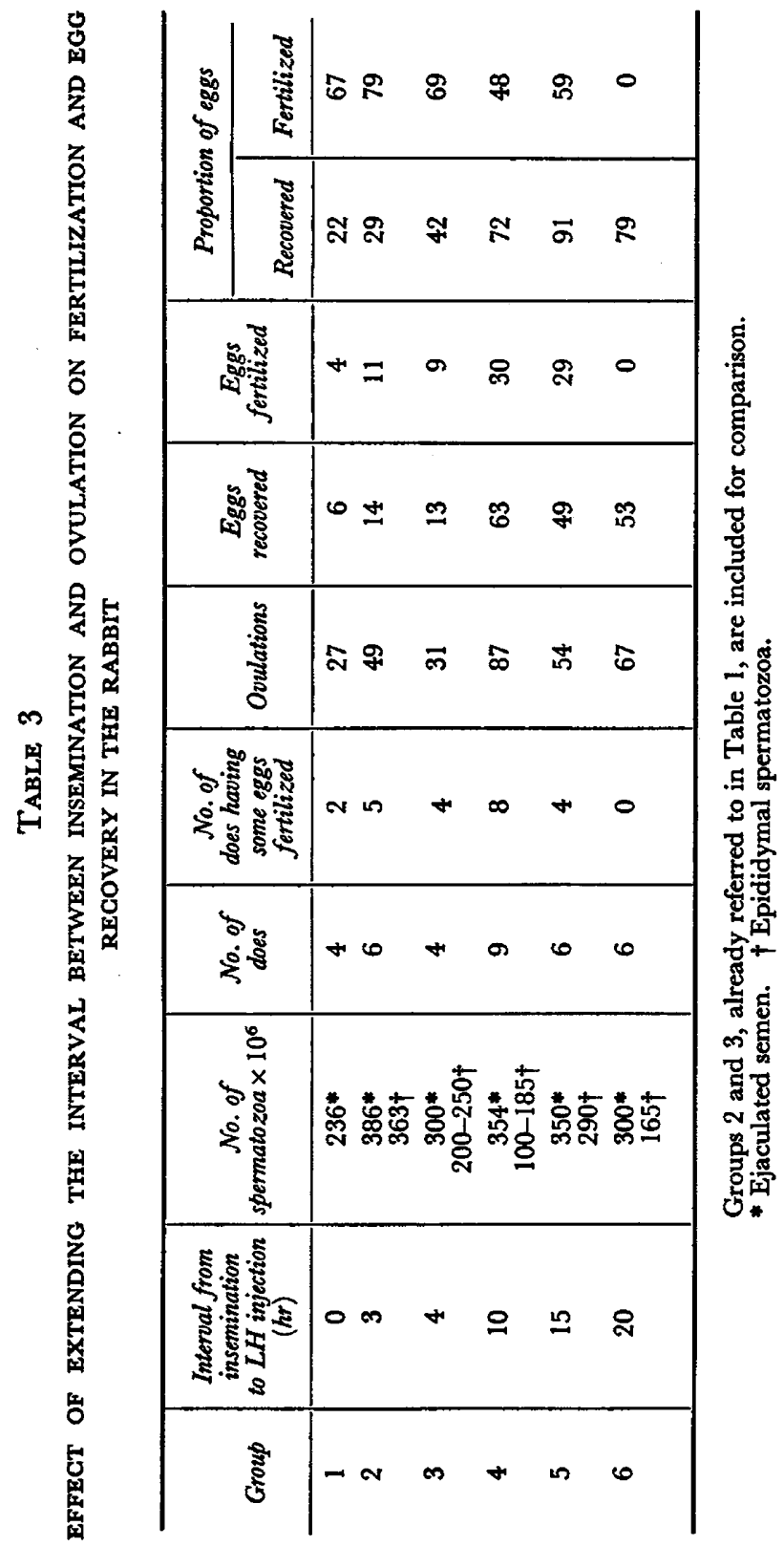


The fact that egg recovery improved as the interval between insemination and ovulation was extended may simply reflect a reduction in sperm numbers through loss of viability.

\section{Fertilization failure}

Apart from the complete failure of fertilization in eleven out of forty does (Table 1, Groups 1 to 5 and Table 3, Groups 1, 4 and 5) there were seven instances out of twenty-nine $(24 \%)$ where fertilization failure was confined to one side of the tract, five involving the left side and two the right. On the contralateral side the proportion of eggs fertilized was $60 \%$ (one), $75 \%$ (two) and $100 \%$ (four does). Such inequality between the two sides is extremely rare under normal conditions of mating.

\section{DISCUSSION}

In confirming the report of Mroueh \& Mastroianni (1966) that the implantation rate is low following intraperitoneal insemination, the present experiments not only explain why this is so but also show that a high proportion of the eggs that survive to implantation are capable of surviving to term. The low implantation rate may have been due to either a low level of fertilization (too few spermatozoa entering tubes?) or loss of eggs (too many spermatozoa?), rather than to an increased incidence of abnormal ova as they suggested. The unexpected failure to recover eggs which should have been present in the tubes is thought to be due to their early destruction by excess spermatozoa, as previously suggested by Noyes, Adams \& Walton (1959). If this was in fact the case, generally the destruction must have been near complete since only rarely were identifiable egg fragments recovered. However, this is not surprising since naked blastomeres are quickly destroyed in the Fallopian tubes, even in the absence of spermatozoa (Moore, Adams \& Rowson, 1968). Thus, the detrimental effect of excess spermatozoa appears to lie primarily in disrupting the integrity of the zona pellucida, which in the rabbit does not in any case afford a block to polyspermy. In oestrous does, Mroueh \& Mastroianni (1966) recovered 4000 to 76,000 (mean 13,000) spermatozoa from the tubes 5 to $6 \mathrm{hr}$ after insemination, whereas normally only 2000 to 6000 are found in the tubes (Austin, 1948; Chang, 1951; Braden, 1953). In normally-mated rats, it has been shown that higher concentrations of spermatozoa at the site of fertilization are significantly associated with the presence of larger numbers of spermatozoa within the eggs (Braden \& Austin, 1954). Since sperm acrosome preparations can destroy eggs in vitro (Srivastava, Adams \& Hartree, 1965), the role of the female tract in restricting the number of spermatozoa reaching the site of fertilization assumes extra significance. Hitherto, the limitation of sperm numbers has been interpreted primarily as a mechanism to reduce the risk of polyspermy (Braden, 1953), though in the case of freshly ovulated eggs, the incidence of polyspermic fertilization is quite low, 1.4\% (Austin \& Braden, 1953).

When insemination preceded the ovulating stimulus by 5 or $6 \mathrm{hr}$, Mroueh \& Mastroianni (1966) obtained no evidence of implantation in six rabbits. However, in the present experiments, fertilization was well maintained with 
intervals of up to $15 \mathrm{hr}$. The fertilization failure observed when insemination took place $30 \mathrm{hr}$ before ovulation may be accounted for by the natural decline in the spermatozoon's fertilizing capacity which is known to occur at this time (Tesh \& Glover, 1966). However, the fact that spermatozoa deposited in the vagina or Fallopian tubes $30 \mathrm{hr}$ before ovulation still gave about $30 \%$ fertilization (Adams, 1968) suggests that the decline may be slightly accelerated as a result of exposure to the peritoneal cavity. At the same time it is recognized that in the former two situations, far greater numbers of spermatozoa were actually placed in the female tract, thereby increasing the probability of greater numbers surviving to ovulation.

In discussing the question of whether capacitation occurs in the peritoneal cavity or in the tube itself, Mroueh \& Mastroianni (1966) did not consider the fact that this process is extended in the tubes. Since many spermatozoa may enter the tubes within an hour of injection (Rowlands, 1958), it appears likely that the spermatozoa are capacitated mainly, if not entirely, in the tubes.

\section{REFERENCES}

Adams, C. E. (1956) A study of fertilization in the rabbit: the effect of post-coital ligation of the Fallopian tube or uterine horn. F. Endocr. 13, 296.

Adams, C. E. (1960) Studies on prenatal mortality in the rabbit, Oryctolagus cuniculus: the amount and distribution of loss before and after implantation. F. Endocr. 19, 325.

Adams, C. E. (1968) Fertilizing capacity of rabbit spermatozoa deposited in the vagina, fallopian tubes or peritoneal cavity. Proc. VIth int. Congr. Anim. Reprod. Artificial Insemination, Paris. (In press).

Adams, C. E. \& Chang, M. C. (1962) Capacitation of rabbit spermatozoa in the Fallopian tube and in the uterus. F. exp. Zool. 15, 159.

Austin, C. R. (1948) Number of sperms required for fertilization. Nature, Lond. 162, 534.

Austin, C. R. \& Braden, A. W. H. (1953) An investigation of polyspermy in the rat and rabbit. Aust. $\mathcal{F}$. biol. Sci. 6, 674.

BRADEN, A. W. H. (1953) Distribution of sperms in the genital tract of the female rabbit after coitus. Aust. 7. biol. Sci. 6, 693.

Braden, A. W. H. \& Austin, C. R. (1954) The number of sperms about the eggs in mammals and its significance for normal fertilization. Aust. 7. biol. Sci. 7, 543.

Chang, M. C. (1951) Fertilization in relation to the number of spermatozoa in the fallopian tubes of rabbits. Annali Ostet. Ginec. 73, 918.

Hadek, R. (1958) Intraperitoneal insemination of rabbit doe. Proc. Soc. exp. Biol. Med. 99, 39.

Moore, N. W., ADAMs, C. E. \& Rowson, L. E. A. (1968) The developmental potential of single blastomeres of the rabbit egg. F. Reprod. Fert. 17, 527.

Mroueh, A. \& MastrolanNi, L., JR (1966) Insemination via the intraperitoneal route in rabbits. Fert. Steril. 17, 76.

Noyes, R. W., Adams, C. E. \& Walton, A. (1959) The transport of ova in relation to the dosage of oestrogen in ovariectomized rabbits. $\mathcal{F}$. Endocr. 18, 108.

Rowlands, I. W. (1958) Insemination by intraperitoneal injection. Stud. Fert. 10, 150.

Srivastava, P. N., Adams, G. E. \& Hartree, E. F. (1965) Enzymic action of acrosomal preparations on the rabbit ovum in vitro. F. Reprod. Fert. 10,61.

Tesh, J. M. \& GLOVER, T. D. (1966) The influence of ageing of rabbit spermatozoa on fertilization and prenatal development. $\mathcal{F}$. Reprod. Fert. 12, 414. 